\title{
Voice-Related Complaints in the Pediatric Population
}

\author{
${ }^{*}, t$, ,Ingrid Verduyckt, * , †Marc Remacle, §Jacques Jamart, †Céline Benderitter, and \|, $\uparrow$ Dominique Morsomme, \\ *§voir, †Louvain-la-Neuve, $\ddagger$ Brussels, ||Liège, ๆSart-Tilman, Belgium
}

\begin{abstract}
Summary: Subjective evaluation of the voice by the patient is routinely assessed in the adult dysphonic population; this is, however, not the case in the pediatric population. There were three objectives of this study: the first goal was to study the ability of children aged 5-13 years to express themselves about physical, emotional, and sociofunctional aspects of their voice. The second goal was to explore if specific voice-related complaints were expressed by dysphonic children as compared with normophonic children. The third goal was to compare the dysphonic children's voice-related complaints with those of their mothers. The overall objective was to set the grounds for the elaboration of a standardized questionnaire in French concerning subjective evaluation of voice in children. Twenty-five dysphonic children with vocal complaint (15 nodules, one polyp, one microweb, eight unspecified) and 55 normophonic children aged 5-13 years were interviewed. The interviews were semistructured based on a canvas of voice-related questions. The dysphonic children's mothers were interviewed with the mean of a written questionnaire and were invited to discuss their answers orally with the examiner. The results were analyzed qualitatively and statistically. A Chi-square test and the Fisher's test were used to analyze the differences between the complaints expressed by the dysphonic and the normophonic children, and a binomial test was used to compare the children's answers with their mothers' answers. The qualitative analysis of the interviews suggests that children are capable of reflecting over their own voice and of giving autonomous information about different aspects of their voice. It also appeared that voice is a complex phenomenon and that it needs to be clearly and cautiously defined to the children. We identified 27 different complaints related to the voice, out of which 17 were significantly more expressed by dysphonic than by normophonic children $(P<0.05)$. Three of the 27 identified complaints show significant discordances between the mothers and the dysphonic children. The results suggest that children are capable of making a subjective and autonomous evaluation of their voice and that dysphonic children experience significantly more voicerelated discomfort than nondysphonic children. The complaints expressed by the dysphonic children and their mothers are not all in concordance. The main conclusion is that a standardized subjective evaluation of the voice, not only by the parents but also by the child him/herself, would be relevant in the assessment of pediatric dysphonia.
\end{abstract}

Key Words: Dysphonia-Subjective evaluation-Children-Parental proxy.

\section{BACKGROUND}

Varying data of prevalence of childhood dysphonia are found in the literature, ranging from $0.12 \%$ to $24 \% .{ }^{1-5}$ The therapeutic approach toward dysphonia in children depends on the etiology of the dysphonia and can be either medical, surgical, speech therapeutic, or combined. A nontherapeutic "wait and see" approach can be held in the case of benign vocal fold lesions or functional dysphonia. Although functional or benign organic childhood dysphonia is generally assumed to disappear by itself during puberty, ${ }^{6-9}$ not all children experience this spontaneous recovery, and some dysphonias persist in adulthood. ${ }^{6}$ Furthermore, it has been shown that childhood dysphonia has an adverse effect on the listener's perception of the child: they are judged more negatively with regard to their physical appearance, their personality, and their cognitive skills by peers and adolescent and adult judges. ${ }^{10-12}$ The results from a recent study involving teachers as judges go in the same direction. ${ }^{13}$

\footnotetext{
Accepted for publication November 20, 2009.

The authors would like to thank the Walloon Region, Belgium, for its support (Grant WALEO II ECLIPSE 616347).

From the *University Hospital of Mont-Godinne, Yvoir, Belgium; †Catholic University of Louvain-l-Neuve, Louvain-la-Neuve, Belgium; łAudio-Phonological Center of the University Hospital of Saint-Luc, Brussels, Belgium; §Department of Biostatistics, University Hospital of Mont-Godinne, Yvoir, Belgium; ||University of Liège, Liège, Belgium; and the $\llbracket$ University Hospital of Lège, Sart-Tilman, Belgium.

Address correspondence and reprint requests to Ingrid Verduyckt, Centre d'Audiophonologie. ESP., Clos Chapelle aux Champs, 30/3040, 1200 Woluwe-Saint-Lambert,

Belgium. E-mail: ingrid.verduyckt@uclouvain.be

Journal of Voice, Vol. 25, No. 3, pp. 373-380

0892-1997/\$36.00

(C) 2011 The Voice Foundation

doi:10.1016/j.jvoice.2009.11.008
}

This can, of course, have adverse educational and psychosocial implications for the child. A commonly held belief is that dysphonic children are not aware or not bothered by their voice disorder; this view is, however, challenged by the findings of Connor et $\mathrm{al}^{14}$-focused interviews with children aged 5-18 years revealed that dysphonic children are aware of and able to express voice-related concerns. Thus, although dysphonia might, in some cases, resolve by itself in adulthood, it can be valuable to treat the dysphonic voice already during childhood. It then seems important that the assessment of voice function in children lives up to the same quality recommendations than that in adults. Voice function is multimodal; its careful and complete assessment comprises laryngological observation, objective acoustic and aerodynamic measures, and subjective perceptual measures. Since 2001, subjective evaluation by the patient is included in the European Laryngological Society's (ELS) guidelines for functional assessment of voice pathology. ${ }^{15}$ In adult populations, the patient's subjective evaluation of his voice is routinely collected by means of standardized questionnaires. ${ }^{16,17}$ They refine the vocal assessment by adding the patient's point of view, and its value is no longer questioned. In fact, the laryngeal, acoustic, aerodynamic, or perceptual severity of a dysphonia is not completely correlated to the patient's subjective evaluation of the disorder's severity. ${ }^{18,19}$ The use of self-evaluation questionnaires gives the clinician a more detailed comprehension of the difficulties encountered by the patient and allows for the elaboration of precise and adapted therapeutic plans, consequently improving patient compliance. Voice therapy is time intensive and demands consistency on the 
part of the patient in both attendance and adherence to the program; questionnaires may help to increase the patient's awareness of the impact of dysphonia and his motivation for change. The questionnaires have also been proven sensitive to posttherapy changes and are an additional and valuable tool in the determination therapy efficiency. ${ }^{20}$

In children, laryngological observations and acoustic, aerodynamic, and perceptual measurements are most often performed; however, subjective evaluation of the vocal disorder by the child $\mathrm{him} /$ herself is not routinely carried out. No standardized instruments exist in French; in English, there are, to our knowledge, three questionnaires for children available for purchase- the Pediatric Voice Outcome Survey, a four-item parental proxy adapted from the Voice Outcome Survey ${ }^{21-23}$; the Pediatric Voice Related Quality of Life questionnaire, a 10-item parental proxy adapted from the Voice Related Quality of Life questionnaire ${ }^{24-26}$; and the Pediatric Voice Handicap Index, a 23-item parental proxy adapted from the Voice Handicap Index. ${ }^{27}$ These questionnaires exist only in the form of parental proxies, and the child's selfevaluation is not considered. There is, to our knowledge, no validated instrument providing both child and parental forms.

Children's capacity of making subjective evaluations of their voices has not been widely studied, but health-related quality of life (HRQoL) related to other chronic diseases, such as childhood asthma, has received more attention. ${ }^{28}$ The literature shows varying outcomes depending on the age of the children, the pathologies studied, the methodologies, and the use or not of parental proxies. Most results underline the utility of questionnaires, allowing for both child and parental reports and essentially; authors seem to agree that children from about 6 years of age have the cognitive abilities to report for some aspects of their HRQoL. Although parent report may provide a substitute for children's HRQoL at a group level, large differences can exist in proxy concordance at the individual level and a double child/parent form is clearly of interest in clinical settings. ${ }^{29,30}$ Double-form questionnaires are regarded as of help in patient care, improving the communication between doctor and patient, allowing the screening of specific problem areas, and allowing the evaluation of changes in patients. ${ }^{28}$

The study conducted by Connors et al addressing the attitudes of children with dysphonia (5-18 years) showed that children's complaints about their voice are not in full concordance with their parents' complaints (concordance varied between $33.3 \%$ and $100 \%)^{14}$ and that it is possible for children, already at a young age, to express themselves about the impact of their vocal disorder.

These results indicate that children are a source that clinicians could and probably should turn toward when assessing the subjective impact of a dysphonia and that a combined child and parental questionnaire could be of interest also in the assessment of dysphonic children. However, assessing own HRQoL requires language skills and cognitive abilities that are not always present in younger children ${ }^{31,32}$; it is thus important to cautiously evaluate the capacity of children to understand and express themselves about the specific health-related area that is subject to evaluation in the children's own language.

\section{OBJECTIVES}

The overall objective of our work is the creation of a standardized double-form questionnaire in French for the subjective evaluation of voice by the child and its parents; no such instrument is available till date. The present study is the first step of this work, dedicated to set the ground for item development by means of interviews with the target group.

The first objective was to examine the skills of Frenchspeaking Belgian children aged 6-12 years in understanding and expressing themselves about their own voice and to observe the vocabulary they use and understand regarding voice.

Our second objective was to identify if dysphonic children expressed voice-related complaints not present in a normophonic control population. Some voice-related difficulties encountered by children could not only be linked to voice disorders but also could be a part of normal voice use or voice function in children.

Our third objective was to analyze if the dysphonic children's mothers would express the same type of complaints as their children. According to the literature on children's self-evaluation of health and the results in Connor's study, it is reasonable to hypothesize that there exist discordances between the mothers and their child. This could have implications for the design of a specific mother form of the questionnaire.

\section{METHODS}

\section{Population}

The population considered was 25 dysphonic children aged 6-13 years $(M=9.6$ years; 15 boys and 10 girls $)$ and their mothers. The children were either recruited through two main voice centers in Belgium, namely, University Hospital of Saint-Luc and Saint-Pierre Hospital in Brussels $(\mathrm{N}=11)$; addressed to us by private speech-language pathologists specialized in vocal disorders $(\mathrm{N}=7)$; or addressed to us by schools that we consulted for the recruitment of normophonic children $(\mathrm{N}=7)$.

\section{Control group}

The control group consisted of 55 normophonic children aged 5-13 years ( $M=8.5$ years; 29 boys and 26 girls). The children were recruited through two ordinary schools in Brussels.

\section{Inclusion and exclusion criteria}

The inclusion criteria for the dysphonic children were:

- An existing vocal complaint, expressed either by the child him/herself or by one of the parents.

- Dysphonia diagnosed either by a laryngologist or perceptually by the two examiners.

The vocal complaint, that is, the fact that either the child's parent or the child him/herself had expressed the need to consult an ear, nose, and throat (ENT) specialist because of his voice, was an important criterion to homogenize the dysphonic group. The organic or physiologic origin of the dysphonia appeared as a less important criterion in this phase of the work. The main 
TABLE 1.

Interview Canvas for the Interviews

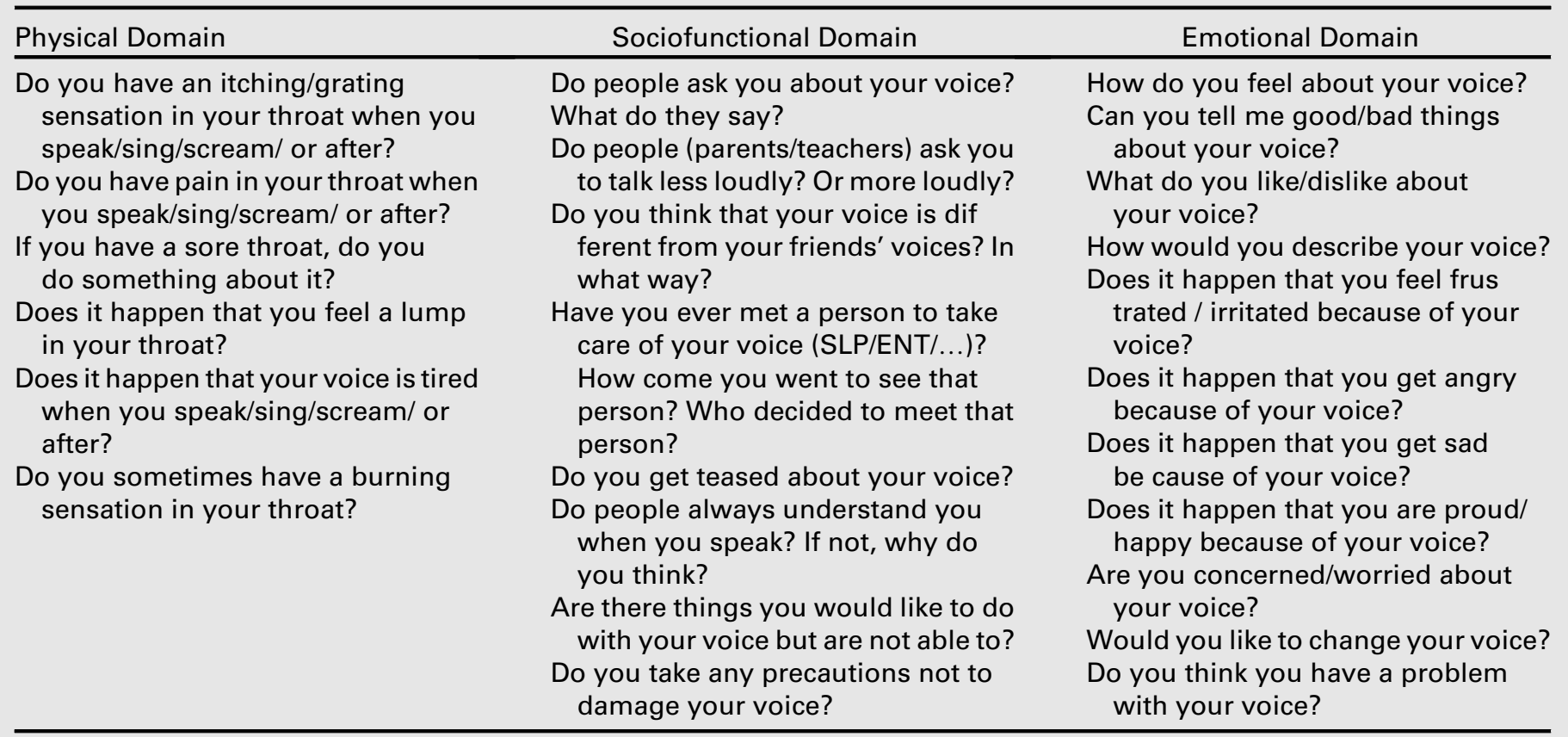

Abbreviation: SLP, speech-language pathologist.

Each response was followed up by appropriate questions, such as When does it occur? In which situations? How often? Do you do something about it? How does it make you feel? The general question "If you think you have problems with your voice, could you tell me what is the most important problem to you?" was also asked to all children.

objective was to collect all existing complaints in dysphonic children with the future purpose to create a tool adapted to children. All children were listened to by at least one speechlanguage pathologist and judged as either normophonic or dysphonic. No deeper voice analysis was performed, although for 16 out of 27 dysphonic children, full voice assessment was performed by an ENT specialist and a speech-language pathologist at the child's first consultation. The main pathology found was nodules $(\mathrm{N}=14)$, which reflects prior findings in the pediatric population. ${ }^{7-9}$

The inclusion criteria for the normophonic children were:

- No actual or former vocal complaint expressed by either the child or one of the parents.

- No dysphonia perceptually identified by the examiners.

We had to refuse some of the normophonic children from the participating schools, because they presented with dysphonic voices although they had no vocal complaint. Those children were not included in the dysphonic group either because of their lack of vocal complaint.

Exclusion criteria for both groups were as follows:

- Having a speech disorder (phonological, lexical, semantic, pragmatic, articulatory).

- Having a cognitive disorder.

This was controlled for by questioning the teachers and/or the parents of all children.

\section{Procedure}

The dysphonic and normophonic children were interviewed either by a speech-language pathologist specialized in voice disorders or a student speech-language pathologist specializing in the same field. The student speech-language pathologist was on her last year of Master and had been previously trained in the protocol by the speech-language pathologist conducting the study. She had 6 months' experience in working with patients.

The interviews were based on a canvas of questions related to the vocal quality and its impact on physical, emotional, and sociofunctional aspects of everyday life. The canvas was developed by two speech-language pathologists and one ENT specialist specialized in voice disorders, familiar to dysphonic children, and inspired by the Connor et al study ${ }^{14}$ (Table 1). The examiner tried to keep the questions as open as possible to guide the children as little as possible. The interviews were preceded by a small introduction aimed to explain the objectives of the interview to the child and to make him comfortable.

Each interview was recorded, either with a Digital Wave Player (Olympus, Hamburg, Germany) or a MicroMemo numeric recorder (Xtreme Accessories, LLC, Weston, FL) applied on an IPod nano 4GB (Apple, France) or a Marantz Pmd 671 recorder (D\&M Professional Europe, UK) equipped with a Sennheiser Hsp4 microphone (Sennheiser Electronics, Germany). Each interview was transcribed by at least one of the examiner; eight of the dysphonic interviews were transcribed by both examiners.

The mothers received a written paper form with both direct and open questions about the impact of their child's vocal 
quality on physical, emotional, and sociofunctional aspects of their child's everyday life. They were invited to fill in the form while their child was interviewed and to return the form to the examiner directly afterward. They were then invited by the examiner to orally comment on their answers or to ask for precisions regarding the questions, but it was optional. Five of the mothers declined to fill in the paper form or wanted to fill it in at home but never returned it.

The transcriptions of the interviews and the parental paper forms were analyzed by both examiners. The children's and the mothers' statements were identified, classified, and reformulated into specific complaints by each examiner on his own. The classifications were then compared, and discordances between the two examiners were discussed until agreement was reached. Each complaint was then classified by three different speechlanguage pathologists specialized in voice disorders in either one of the physical, emotional, or sociofunctional category.

Some of the dysphonic children participating in the study had already been seen by a speech-language pathologist and had benefited from one or more therapy sessions $(\mathrm{N}=15)$. To exclude a possible bias owing to the contact with a speechlanguage pathologist and the reassurance or increased awareness of the voice problems it might entail, we analyzed the results of the group with at least one speech therapy session and the group without any speech therapy separately.

\section{Statistical analyses}

All analyses were carried out with the SPSS software (version 11.5, 2002; SPSS Inc, Chicago, Illinois). A Chi-square test and a Fisher's test were used to evaluate the distribution of the symptomatic and asymptomatic answers in the dysphonic and normophonic groups. A Chi-square test was also used to determine the impact of the variable "speech-therapy" on the dysphonic children's answers. A binomial test was used to analyze the concordance between the answers given by the children and their mothers.

\section{RESULTS}

\section{Descriptive statistics}

Of the 25 dysphonic interviews, one had to be excluded from the result analysis because of poor recording. A total of 24 interviews were analyzed.

Of the 25 solicited mothers, 20 returned the parental questionnaire; one was excluded from the result analysis because of poor recording of her child. A total of 19 questionnaires were analyzed. All 55 normophonic interviews could be included in the result analysis.

\section{Qualitative analysis}

Twenty-seven distinct complaints were clearly identified by the two examiners. Twenty-one of them were identically classified into the physical, emotional, or sociofunctional category by three speech-language pathologists; three items were more difficult to classify, and agreement was reached between the three judges after discussion. The classification is not definite and has not been analyzed statistically; it is essentially used to simplify the presentation of the items.

It is important to keep in mind that the original work is in French and that a translation is never optimal. It is especially difficult to adequately translate words expressing subjective feelings and sensations.

\section{Statistical analysis}

Dysphonic children versus normophonic children. Seventeen of 27 complaints were expressed more to a significant degree by the dysphonic children: five of 10 physical (Table 2), seven of 10 emotional (Table 3), and five of seven sociofunctional $(P<0.05)$ (Table 4$)$.

Dysphonic children with speech therapy versus dysphonic children without speech therapy. Two of 27 complaints were expressed more to a significant level by the dysphonic children having seen a speech-language pathologist: One emotional and one sociofunctional $(P<0.05)$ (Table 5).

Mothers versus children. Three of the 27 identified complaints show a significant discordance between the mothers and the children (Table 6): one physical complaint that the children express more than their mothers and two emotional complaints that the mothers express more than their children $(P<0.05)$. There is no significant discordance for the sociofunctional items.

\section{DISCUSSION}

\section{Children's ability to express themselves about their voice}

During the interviews, it appeared clearly that voice is a complex phenomenon and that most children, especially the younger ones, mix up voice with articulatory, phonological, or lexical features (eg, "I have problems with my voice because when I speak Polish with my dad I don't know the right way to say the words"). Physical sensations specific to voice use were sometimes mixed up with physical sensations linked to general physical effort (eg, "After running as fast as I can, I lose my voice because I breathe so heavily"; "When I have my woolen scarf on, my throat gets itchy"). Several children gave account for voice difficulties, such as pain, itching, or scraping sensations in the throat, but when asked to be more specific, it appeared that they were relating to incidents where they had a cold or the flu and that it never occurred otherwise. It also appeared that the children needed to contextualize the voice to specific situations: some children, when asked if they sometimes experienced throat pain or vocal fatigue answered that it never occurred, although several of them, later in the interview, spontaneously described vocal situations where they said they had to rest their voices, because it was tired or because their throat hurt and that it was a signal for them to be quiet. These observations have implications for the future design of a standardized questionnaire: voice has to be clearly defined and differentiated from other speech features to the child before the assessment; the use of situation-specific questions could probably facilitate the children 
TABLE 2.

Physical Concerns Expressed by Dysphonic Children Versus Normophonic Children

\begin{tabular}{|c|c|c|c|c|}
\hline Physical Items & \multicolumn{2}{|c|}{ N Expressing the Item } & Symptomatic Answers & $P$ Value \\
\hline $\mathrm{P} 1: \mathrm{A}$ lump in the throat & 46 & 21 & $\begin{array}{l}\text { No }<D \\
7.1 \%<38.1 \%\end{array}$ & $\begin{array}{l}0.002^{*} \\
0.0027^{\dagger}\end{array}$ \\
\hline P2: Burning sensation in the throat & 44 & 16 & $\begin{array}{l}\text { No }=D \\
25 \%=25 \%\end{array}$ & NS \\
\hline P3: Tickling sensation in the throat & 53 & 23 & $\begin{array}{l}\text { No }<D \\
13.2 \%<56.5 \%\end{array}$ & $\begin{array}{r}<0.001^{*} \\
0.0002^{\dagger}\end{array}$ \\
\hline P4: Scratching/itching sensation in the throat & 51 & 21 & $\begin{array}{l}\text { No }<D \\
9.8 \%<47.6 \%\end{array}$ & $\begin{array}{r}<0.001^{*} \\
0.0008^{\dagger}\end{array}$ \\
\hline P5: Pain in the throat associated to talking & 50 & 22 & $\begin{array}{l}\text { No }<\text { D } \\
22 \%<63.6 \%\end{array}$ & $\begin{array}{c}<0.001^{*} \\
0.0011^{\dagger}\end{array}$ \\
\hline P6: Pain in the throat associated to singing & 53 & 21 & $\begin{array}{l}\text { No }<D \\
20.8 \%<47.6 \%\end{array}$ & $\begin{array}{l}0.021^{*} \\
0.0428^{\dagger}\end{array}$ \\
\hline P9: Vocal fatigue associated to singing & 45 & 20 & $\begin{array}{l}\text { No > D } \\
35.6 \%>35 \%\end{array}$ & NS \\
\hline P10: Vocal fatigue associated to screaming & 50 & 21 & $\begin{array}{l}\text { No }<\text { D } \\
58 \%<66.7 \%\end{array}$ & NS \\
\hline
\end{tabular}

to project themselves and to recall their subjective feelings and sensations. The interviews with the normophonic children were conducted to a greater extent, as those children had less spontaneous concerns, and most of them had never reflected over their voice and, thus, lacked words to describe it or to analyze subjective feelings about it.

\section{Normophonic versus dysphonic children}

In the physical category, five of 10 complaints significantly differentiated the dysphonic and the normophonic groups (Table 1). Dysphonic children reported having a "lump" in the throat, a tickling or itching sensation in the throat, and pain in the throat associated to singing or talking to a greater extent than normophonic children. The feeling of a lump in the throat or itching or tickling sensation in the throat are symptoms that could be associated to gastroesophageal or pharyngolaryngeal reflux, which has been considered as one of the possible cause of childhood dysphonia. ${ }^{33,34}$ Other symptoms of reflux, such as the need to cough or clear one's throat often, were not expressed spontaneously by the children; it may be attributed to the fact that the relationship to the voice is not easy to see. The examiners did not ask for those symptoms directly; they should be included in future works. Surprisingly, the item "burning sensation in the throat," which is also a symptom of reflux, showed no significant differences between the two groups.

The fact that pain associated with talking or singing is significantly more expressed in dysphonic children could be the reflection of their need to strain during normal or usually "light" vocal use. The low report and the lack of difference between the two groups regarding vocal fatigue associated to talking, singing, or screaming is of interest. Vocal fatigue could be hypothesized to be more present in dysphonic than normophonic children, but it is a more discrete sensation than pain and might be overlooked easier. This has an implication for therapy, as it underlines the interest of working on proprioception to make dysphonic children aware of the sensation of vocal fatigue as an early sign of vocal strain and as an indication of the need to rest the voice. ${ }^{35}$

In the emotional category, seven of 10 items significantly differentiated the two groups (Table 2). Feeling frustrated, angry, embarrassed, and dissatisfied with one's voice as well as disliking one's voice, describing it in negative terms, or being asked questions because of one's voice is significantly more expressed by dysphonic children. The feelings of anger, frustration, and embarrassment were expressed by some in relation to the need to treat the voice and the time such a treatment would take, whereas others associated those feelings to situations where the voice did not work satisfyingly enough (being unable to sing correctly, to read aloud, to scream when on scout camp, etc.). Ten of the 21 dysphonic children who described their voice in what was judged as negative terms by the examiners (eg, "broken voice": "voix cassée"; "rough voice": "voix rauque"; "damaged voice": "voix abîmée"; or, for girls, the complaint of sounding like a boy) also stated that they liked their voices. It seems important to highlight that describing one's voice in terms that are commonly associated to disordered voices does not 
TABLE 3.

Emotional Concerns Expressed by Dysphonic Children Versus Normophonic Children

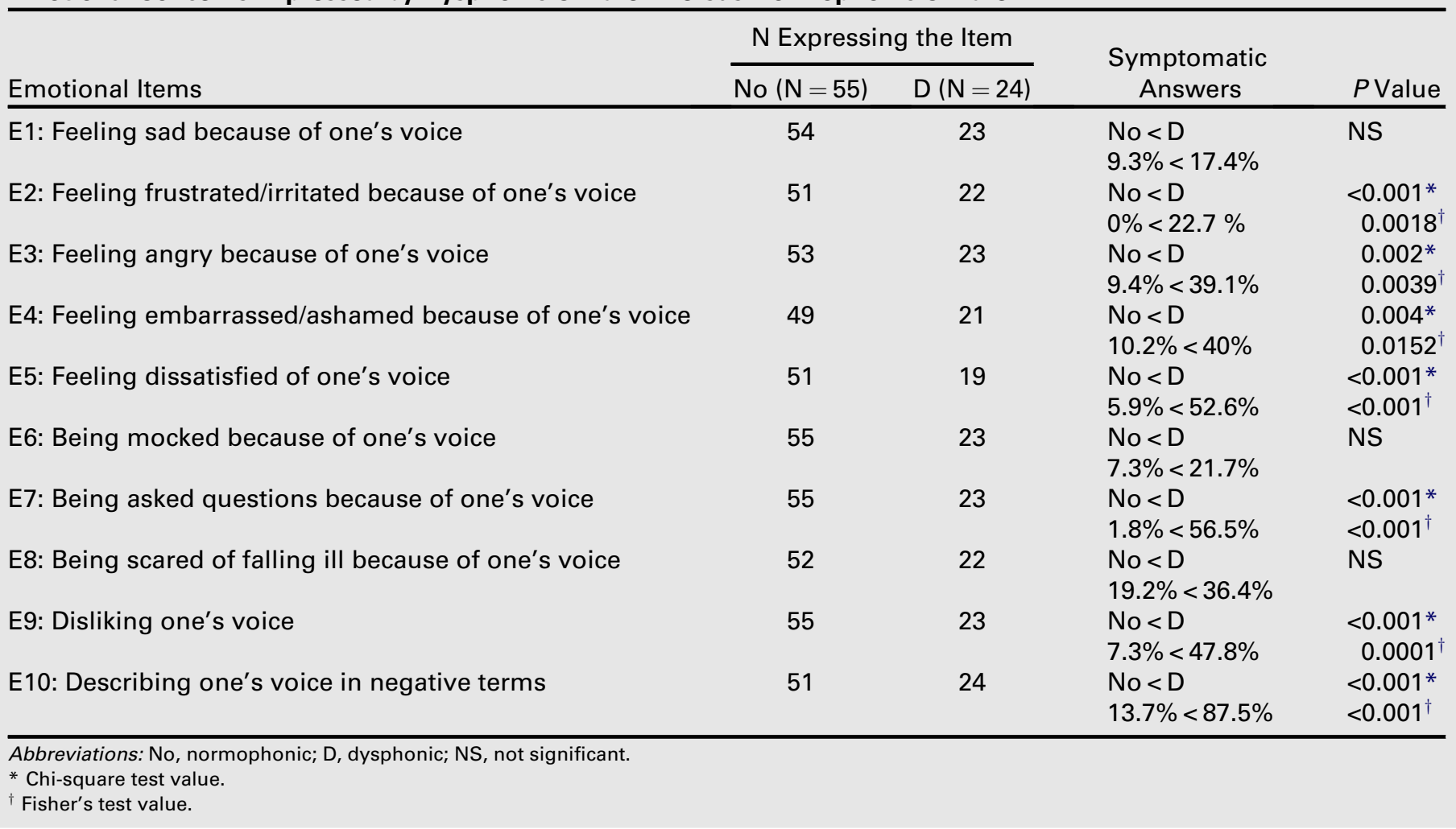

automatically imply the dislike of one's voice. This has, of course, implication for therapy where it is important that both patient and clinician strive after the same goal; what might appear as negative for the speech-language pathologist (deviant vocal quality) might not bother the child at all.
In the sociofunctional category, five of seven items significantly differentiated the two groups (Table 3 ). The perception of having a different voice as compared with other children was significantly more expressed by dysphonic children. It should be noted that the children did not always give a value

TABLE 4

Sociofunctional Concerns Expressed by Dysphonic Children Versus Normophonic Children

\begin{tabular}{|c|c|c|c|c|}
\hline Sociofunctional Items & \multicolumn{2}{|c|}{ N Expressing the Item } & $\begin{array}{c}\text { Symptomatic } \\
\text { Answers }\end{array}$ & $P$ Value \\
\hline SF1: Being asked to talk more loudly & 55 & 24 & $\begin{array}{l}\text { No }>\text { D } \\
60 \%>50 \%\end{array}$ & NS \\
\hline SF2: Being asked to talk less loudly & 55 & 24 & $\begin{array}{l}\text { No }<D \\
58.2 \%<79.2 \%\end{array}$ & NS \\
\hline SF3: Not being well understood when speaking & 51 & 22 & $\begin{array}{l}\text { No }<\mathrm{D} \\
23.5 \%<68.2 \%\end{array}$ & $\begin{array}{r}<0.001^{*} \\
0.0005^{\dagger}\end{array}$ \\
\hline SF4: Having a different voice as compared with other children & 54 & 23 & $\begin{array}{l}\text { No }<D \\
51.9 \%<78.3 \%\end{array}$ & $\begin{array}{l}0.031^{*} \\
0.0422^{\dagger}\end{array}$ \\
\hline SF5: Not being able to sing because of one's voice & 50 & 22 & $\begin{array}{l}\text { No }<\text { D } \\
4 \%<63.6 \%\end{array}$ & $\begin{array}{l}<0.001^{*} \\
<0.001^{\dagger}\end{array}$ \\
\hline SF6: Not being able to scream because of one's voice & 49 & 22 & $\begin{array}{l}\text { No }<\text { D } \\
6.1 \%<40.9 \%\end{array}$ & $\begin{array}{r}<0.001^{*} \\
0.0008^{\dagger}\end{array}$ \\
\hline
\end{tabular}

Abbreviations: No, normophonic; D, dysphonic; NS, not significant.

* Chi-square test value.

$\dagger^{\dagger}$ Fisher's test value. 
TABLE 5.

Concerns Expressed by Dysphonic Children With Speech Pathology Versus Dysphonic Children Without Speech Pathology

\begin{tabular}{lccc}
\hline & \multicolumn{2}{c}{$\mathrm{N}$ Expressing the Item } & \\
\cline { 2 - 3 } Items & No SP $(\mathrm{N}=9)$ & $\mathrm{SP}(\mathrm{N}=15)$ & Symptomatic Answers \\
\hline $\begin{array}{l}\text { E2: Feeling frustrated/irritated } \\
\text { because of one's voice }\end{array}$ & 0 & 5 & No SP $<\mathrm{SP}$ \\
$\begin{array}{l}\text { SF7: Having problems } \\
\text { because of one's voice }\end{array}$ & 6 & 14 & 0.034 \\
\hline Abbreviation: SP, speech pathology. & & No SP $<8$ SP \\
\end{tabular}

to this statement and, when they did, it could be either positive or negative. We note that eight of the 18 dysphonic children who felt that their voice was unique also stated that they liked their voice. Other sensitive items concerned restrictions in the ability to sing or scream because of one's voice. These were main concerns in the children who were engaged in chorus or scouting activities.

A total of 27 concerns were expressed in all; only 17 of them were significantly more expressed by the dysphonic group than by the normophonic group. This supports the hypothesis that some vocal concerns are linked to habitual voice use in children. However, the frequency of occurrence of the symptoms, which might be a determinant factor in the differentiation of the two groups, was not taken into account. We found it surprising that the item "Being asked to talk less loudly" did not reach significance. Intuitively, it seems natural to hypothesize that dysphonic children would have an increased habitual intensity, the mass on the vocal fold hindering good closure and vibration if subglottic pressure is not increased. The notion of frequency would probably differentiate the two groups: speaking too loud once in a while is probably common for most of the children; doing it most of the time might be specific to dysphonic children. This could also be true for other items, such as "burning sensation in the throat," which were not differentiating the two groups. This has implications for the design of a future questionnaire that should give the possibility to account for the frequency of the symptoms.

\section{Speech therapy versus no speech therapy}

Two items differentiated significantly the dysphonic children having had at least one speech therapy session. "Feeling frustrated/irritated because of one's voice" and "Having problems because of one's voice" were expressed more in the speech therapy group. It is possible that the consideration of the voice as a "problem" is amplified by the fact that a treatment is undertaken. For some children, it even appeared that the treatment in itself was the source of the problem (time consuming, curtailing free play time, demanding boring exercises, etc.) and, thus, yielded frustration or irritation. However, another cause given for frustration/irritation was the uncontrollability of the voice. For the rest of the items, the differences observed between the normophonic and the dysphonic children cannot be accounted for by the speech therapy group.

\section{Mothers versus children}

Three items showed a significant discordance between maternal and child answers. The discordance does not consistently point in the same direction; mothers answered more symptomatically than their children on emotional items, including sadness and frustration associated with the voice. Children gave more symptomatic answers than their mothers on a physical item "pain in the throat associated to talking." Those results replicate in part the Connor et $\mathrm{al}^{14}$ observations with more emotional complaints found in the parents and more physical complaints found in the children. Theunissen et $\mathrm{al}^{30}$ found discordances in parental and child answers concerning physical health status: children gave more symptomatic answers, although parents gave more symptomatic answers regarding negative affectivity linked to physical health status. It has been observed in the literature that concordance between parental and child report depends on the type of domain: emotional facets, more abstract and may be less openly talked about, often give the lowest concordances, whereas functional items yield the highest. ${ }^{32}$ The implications of these findings are limited owing to the number

TABLE 6.

Concerns Expressed by the Mothers Versus the Children

\begin{tabular}{lccc}
\hline Items & Answering Diads N & Symptomatic Answers & $P$ Value \\
\hline P5: Pain in the throat associated to talking & 19 & $\mathrm{M}<\mathrm{C}$ & 0.039 \\
E1: Feeling sad because of one's voice & 16 & $\begin{array}{c}21 \%<63.1 \% \\
\mathrm{M}>\mathrm{C}\end{array}$ & 0.021 \\
E2: Feeling frustrated/irritated because of one's voice & 18 & $\begin{array}{c}62.5 \%>12.5 \% \\
\mathrm{M}>\mathrm{C}\end{array}$ & 0.012 \\
\hline
\end{tabular}

Abbreviations: $\mathrm{M}$, mother; $\mathrm{C}$, child. 
of the participating dyads $(\mathrm{N}=19)$. However, we believe that our results support the interest of addressing both parents and children to complete the understanding of the impact of dysphonia.

\section{CONCLUSION}

Our study suggests that children aged 6-12 years have the ability to express themselves about their voice; the children in our study were able to account for physical, emotional, and sociofunctional aspects of their voice if voice was properly defined.

Dysphonic children expressed significantly more complaints about their voice than normophonic children, supporting the fact that they were aware of and could account for vocal symptoms and their impact on different aspects of their life. Discordances are observed between the complaints expressed by the children and by their mothers, although not to a large extent.

The interest of including subjective evaluation of the voice, not only by the parents but also the child him/herself, in the assessment of dysphonic children, is supported. Further studies are needed to define the design of a questionnaire permitting the standardized assessment of children's and parents' subjective evaluation of voice.

\section{REFERENCES}

1. Carding P, Roulstone S, Northstone K, The ALSPAC Study Team. The prevalence of childhood dysphonia: a cross-sectional study. $J$ Voice. 2005;20:623-630.

2. Duff MC, Proctor A, Yairi E. Prevalence of voice disorders in African American and European American preschoolers. J Voice. 2003;18:348-353.

3. Kiliç MA, Okur E, Yildrim I, Güzelsoy S. The prevalence of vocal fold nodules in school age children. Int J Pediatr Otorhinolaryngol. 2003;68:409-412.

4. McKinnon DH, McLeod S, Reilly S. The prevalence of stuttering, voice and speech-sound disorders in primary school students in Australia. Lang Speech Hear Serv Sch. 2007;38:5-15.

5. Powell M. A longitudinal study of the prevalence of voice disorders in children from a rural school division. J Commun Dis. 1989;22:375-382.

6. De Bodt MS, Ketelslagers K, Peeters T, et al. Evolution of vocal fold nodules from childhood to adolescence. $J$ Voice. 2005;21:151-156.

7. Dejonckere PH. Voice problems in children: pathogenesis and diagnosis. Int J Pediatr Otorhinolaryngol. 1999;49:311-314.

8. Gray SD, Smith ME, Schneider H. Voice disorders in children. Int J Pediatr Otorhinolaryngol. 1996;43:1357-1384.

9. Hirschberg J, Dejonckere PH, Hirano M, Mori K, Schultz-Coulon HJ, Vrticka K. Voice disorders in children. Int J Pediatr Otorhinolaryngol. 1995;32:109-125.

10. Ruscello DM, Lass NJ, Podbesek J. Listener's perceptions of normal and voice-disordered children. Folia Phoniatr. 1988;40:290-296.

11. Lass NJ, Ruscello DM, Stout LL, Hoffmann FM. Peer perception of normal and voice disordered children. Folia Phoniatr. 1991;43:29-35.

12. Lass NJ, Ruscello DM, Bradshaw KH, Blankenship B. Adolescents' perceptions of normal and voice-disordered children. J Commun Disord. 1991;24:267-274.

13. Ma E, Yu C. Teachers' attitudes towards children with voice problems; Presented at: the 8th Pan European Voice Conference, August 26, 2009; Dresden, Germany.

14. Connor NP, Cohen SB, Theis SM, Thiebeault SL, Heatley DG, Bless DM. Attitudes of children with dysphonia. J Voice. 2008;22:197-209.
15. Dejonckere PH, Bradley $\mathrm{P}, \mathrm{Clement} \mathrm{P}$, et al. A basic protocol for functional assessment of voice pathology, especially for investigating the efficacy of (phonosurgical) treatments and evaluating new assessment techniques. Guideline elaborated by the Committee on Phoniatrics of European Laryngological Society (ELS). Eur Arch Otorhinolaryngol. 2001;258:77-82.

16. Hogikyan ND, Sethuraman G. Validation of an instrument to measure voice-related quality of life (V-RQOL). J Voice. 1999;13:557-569.

17. Deary IJ, Wilson JA, Carding PN, MacKenzie K. VoiSS: a patient-derived Voice Symptom Scale. J Psychosom Res. 2003;54:483-489.

18. Jacobson BH, Johnson A, Grywalski C, Silbergleit A, Jacobson G, Benninger MS, Newman CW. The Voice Handicap Index (VHI) development and validation. Am J Speech Lang Pathol. 1997;6:66-70.

19. Woisard V, Bodin S, Yardeni E, Puech M. The Voice handicap Index: correlation between subjective patient response and quantitative assessment of voice. J Voice. 2006;21:623-631.

20. Steen IN, MacKenzie K, Carding PN, Webb A, Deary IJ, Wilson JA. Optimizing outcome assessment of voice interventions, II: sensitivity to change of self-reported and observer-rated measures. J Laryngol Otol. 2008;122:46-51.

21. Hartnick CJ. Validation of a pediatric voice quality-of-life instrument: the pediatric voice outcome survey. Arch Otolaryngol Head Neck Surg. 2002; 128:919-922.

22. Hartnick CJ, Volk M, Cunningham M. Establishing normative voice-related quality of life scores within the pediatric otolaryngology population. Arch Otolaryngol Head Neck Surg. 2003;129:1090-1093.

23. Mirasola KL, Braun N, Blumin JH, Kerschner JE, Merati AL. Self-reported voice-related quality of life in adolescents with paradoxical vocal fold dysfunction. $J$ Voice. 2008;22:373-378.

24. Boseley ME, Cunningham MJ, Volk MS, Hartnick CJ. Validation of the Pediatric Voice-Related Quality-of-Life survey. Arch Otolaryngol Head Neck Surg. 2006;132:717-720.

25. Merati AL, Keppel K, Braun NM, Blumin JH, Kerschner JE. Pediatric voice-related quality of life: findings in healthy children and in common laryngeal disorders. Ann Otol Rhinol Laryngol. 2008;117:259-262.

26. Blumin JH, Keppel KL, Braun NM, Kerschner JE, Merati AL. The impact of gender and age on voice related quality of life in children: normative data. Int J Pediatr Otorhinolaryngol. 2008;72:229-234.

27. Zur KB, Cotton S, Kelchner L, Baker S, Weinrich B, Lee L. Pediatric Voice Handicap Index (pVHI): a new tool for evaluating pediatric dysphonia. Int J Pediatr Otorhinolaryngol. 2007;71:77-82.

28. Baars RM, van der Pal SM, Koopman HM, Wit JM. Clinicians' perspective on quality of life assessment in paediatric clinical practice. Acta Paediatr. 2004;93:1356-1362.

29. le Coq EM, Boeke AJP, Bezemer PD, Colland VT, van Eijk JThM. Which source should we use to measure quality of life in children with asthma: the children themselves or their parents? Comparing the psychometric properties of a child \pm and a parent \pm report scale. Qual Life Res. 2000;9:625-636

30. Theunissen NCM, Vogels TGC, Koopman HM, et al. The proxy problem: child report versus parent report in health-related quality of life research. Qual Life Res. 1998;7:387-397.

31. Cremeens J, Eiser C, Blades M. Characteristics of health-related self-report measures for children aged three to eight years: a review of the literature. Qual Life Res. 2006;15:739-754.

32. Jokovic AD, Locker D, Guyatt G. How well do parents know their children? Implications for proxy reporting of child health-related quality of life. Qual Life Res. 2004;13:1297-1307.

33. Block B, Brodsky L. Hoarseness in children: the role of laryngopharyngeal reflux. Int J Pediatr Otorhinolaryngol. 2007;71:1361-1369.

34. Belafski CP, Postma NG, Amin RM, Koufman AJ. Symptoms and findings of laryngopharyngeal reflux. Ear Nose Throat J. 2002;81(Suppl 2).

35. Welham NV, Maclagan AM. Vocal fatigue: current knowledge and future directions. $J$ Voice. 2003;17:21-30 